\title{
SOBRE A IGUALDADE DE OPORTUNIDADES EDUCACIONAIS: ANÁLISE ADPF 186 \\ ON EQUALITY OF EDUCATIONAL OPPORTUNITIES: A CRITICAL APPROACH TO THE CASE LAW ADPF 186
}

\author{
Yuri Schneider" \\ Robison Tramontina**
}

Resumo: Trata-se de analisar a Ação por Descumprimento de Preceito Fundamental $(\mathrm{ADPF})$ n. 186. Tal ação, movida pelo partido Democratas em 2009, pedia que o Supremo Tribunal Federal declarasse como inconstitucional a medida tomada pela Universidade de Brasília que estabelecia uma reserva de $20 \%$ das vagas com base no critério étnico-racial. O objetivo nesta análise foi identificar o principal argumento utilizado pela Corte Constitucional para declarar a constitucionalidade do referido critério. Tendo como referência os votos dos Ministros do Supremo Tribunal Federal, conclui-se que o princípio da igualdade material é o fundamento da decisão que declara constitucional a reserva de vagas para negros e pardos no que se refere ao acesso ao ensino superior.

Palavras-chave: Ações afirmativas. Constitucionalidade. Igualdade material.

\begin{abstract}
This paper addresses the constitutional reasons set forth on the case ruled by the Federal Supreme Court of Brasil concerning the so-called quotes to colored people instituted by the public University of Brasília. In 2009, Democrats Party claimed to Supreme Court to uphold the unconstitutionality of the rules stablished by the University of Brasília which created a $20 \%$ reservation of its seats based on ethnic and racial criteria. The purpose of this paper is to identify the main arguments adopted by the Court toward to declare the constitutionality of such criteria. Regarding the votes of the Supreme Court's Justices, the paper states that the principle of substantive equality is, in fact, the basis of such decision.
\end{abstract}

Keywords: Affirmative action. Constitutionality. Substantive equality.

\footnotetext{
" Doutor em Direito Público pela Universidade do Vale do Rio dos Sinos; Professor do Programa de Pós-graduação em Direito (Mestrado) da Universidade do Oeste de Santa Catarina; Advogado; yurisdr@hotmail.com

** Doutor em Filosofia pela Pontifícia Universidade Católica do Rio Grande do Sul; Professor do Programa de Mestrado em Direitos Fundamentais da Universidade do Oeste de Santa Catarina; Rua Oiapoc, 211, Agostini, 89900-000, São Miguel do Oeste, Santa Catarina, Brasil; robison.tramontina@unoesc.edu.br
} 


\section{Introdução}

As revoluções liberais do século XVIII alçaram a igualdade a princípio político e jurídico das principais constituições democráticas ocidentais. Assim, elas operaram uma alteração expressiva, uma ruptura, no modo de se compreender o homem, a sociedade, em seus diversos aspectos, e o direito. Pode-se dizer que, com o reconhecimento do princípio da igualdade nos principais diplomas jurídicos, houve uma horizontalização ontológica e epistemológica do mundo. E por terem sido uma das principais responsáveis, pelo menos no campo político e jurídico, aquelas se constituem como marcos importantes da história da conquista, consolidação e efetivação dos direitos humanos/fundamentais.

Contudo, o reconhecimento e a positivação de um determinado princípio jurídico não implicam a efetividade deste. Em outros termos, o reconhecimento jurídico não resulta necessariamente em reconhecimento prático (moral e social). A "história" do princípio da igualdade é um testemunho de tal fenômeno. Por exemplo, causa certo estranhamento, a primeira vista, que o Bill of Rights (1176), em seu primeiro artigo, assegure que todos os homens são livres e iguais, e paradoxalmente, naquele momento histórico, haver a prática e o reconhecimento legal da escravidão de negros nos EUA.

O "paradoxo da igualdade"1, assim se pode denominá-lo, será uma constante nos séculos posteriores na maior parte das sociedades democráticas ocidentais. Tal paradoxo não apenas se exterioriza na questão racial, mas também em outras, como, por exemplo, na do gênero. Contudo, na presente investigação, apenas aquela é objeto de análise. Um dos países ocidentais que o referido paradoxo se fez/faz patente é o Brasil. Uma análise acurada da história jurídica e social brasileira fornecerá material farto para comprovar tal afirmação.

As incongruências de mão dupla existentes entre o âmbito normativo e o fático, sugeridas pelo paradoxo da igualdade, geram em determinados contextos (histórico, político e social) sérias controvérsias jurídico-constitucionais. Uma delas é a recente discussão vinculada à questão racial expressa na apreciação pelo Supremo Tribunal Federal (STF) da Ação por Descumprimento de Preceito Fundamental (ADPF) n. 186.

Em 20 de julho de 2009, o Partido Democratas (DEM) ingressou no Supremo Tribunal Federal (STF) com uma Arguição de Descumprimento de Preceito Fundamental (ADPF), com pedido de liminar, visando à declaração de inconstitucionalidade de atos da Universidade de Brasília (UnB), do Conselho de Ensino, Pesquisa e Extensão (CEPE) da UnB e do Centro de Promoção de Eventos da Universidade de Brasília (Cespe), que instituíram o sistema de reserva de vagas com base em critério

1 Usa-se a expressão como entendida por Alexy (2009): "Toda igualdade de direito tem por consequência uma desigualdade de fato, e toda desigualdade de fato tem como pressuposto uma desigualdade de direito." 
étnico-racial, reservando $20 \%$ das vagas às cotas étnico-raciais, no processo de seleção para o ingresso de estudantes naquele ano.

Referida ADPF tinha como condão que o STF declare como inconstitucional a reserva de vagas para negros e pardos estabelecida pela UnB, o que suscitou sólido e intenso debate ${ }^{2}$ acerca da adoção de ações afirmativas dessa natureza, motivo que enseja e pretexta uma análise cuidadosa desta.

Dessa forma, trata-se de analisar a referida ação com o propósito de identificar o principal princípio jurídico que fundamentou a decisão do STF. Para alcançar êxito em tal empreendimento, usar-se-á a seguinte trajetória argumentativa:

a) apresentação dos argumentos arrolados na Petição inicial movida pelo Partido Democratas (DEM);

b) exposição dos argumentos do Ministro Gilmar Mendes ao avaliar o pedido liminar;

c) detalhamento dos votos dos Ministros em plenário;

d) considerações teóricas acerca do princípio da igualdade material.

\section{Argumentos arrolados na Petição Inicial}

Na ação movida, o Partido Democratas (DEM) alegou que as políticas adotadas na Universidade de Brasília (UnB) estariam ferindo diversos preceitos fundamentais da Constituição Federal, entre eles, o princípio republicano (art. $1^{\circ}$, caput) e a dignidade da pessoa humana (art. $1^{\circ}$, III), a vedação ao preconceito de cor e à discriminação (art. $\left.3^{\circ}, \mathrm{IV}\right)$, o repúdio ao racismo (art. $\left.4^{\circ}, \mathrm{VIII}\right)$, a igualdade (art. $5^{\circ}, c a-$ put), a legalidade (art. $\left.5^{\circ}, \mathrm{II}\right)$, o combate ao racismo (art. $\left.5^{\circ}, \mathrm{XLII}\right)$, o devido processo legal e o princípio da proporcionalidade (art. $5^{\circ}$, LIV); os princípios da legalidade, da impessoalidade, da razoabilidade, da publicidade e da moralidade (art. 37, caput); o direito universal à educação (art. 205); igualdade nas condições de acesso ao ensino (art. 206, caput e I); a autonomia universitária (art. 207, caput); e, por fim, o princípio meritocrático (art. 208, V).

Entendeu-se, inicialmente, que os princípios constitucionais apontados como violados estariam revestidos de uma magnitude indiscutível na axiologia da Constituição de 1988, por isso foram tidos como autênticos preceitos fundamentais, admitindo-se a utilização da ADPF, pois o objeto impugnado se resumiu a atos infralegais, de estatura hierárquica secundária e insuscetível de controle abstrato por Ação Direta de Inconstitucionalidade.

\footnotetext{
${ }_{2}$ As discussões sobre a adoção de ações afirmativas dessa natureza têm uma trajetória relativamente recente no Brasil. Pode-se identificar a Constituição Federal de 1988 como o março jurídico. A partir disso, são diversas e notórias as contribuições teóricas e doutrinárias sobre a temática. Assim, o que se quer ressaltar é que em 2009, com a $\mathrm{ADPF}$, tem-se o auge da discussão sobre a questão do critério étnico-racial para o ingresso no ensino superior.
} 
Resumidamente, a peça inicial defende que os atos estatais da Universidade de Brasília atingiram os preceitos fundamentais descritos porque estipular a criação da reserva de vagas de $20 \%$ para negros no acesso às vagas universais instituiria um verdadeiro "Tribunal Racional" por meio do qual os direitos dos indivíduos ficariam, sorrateiramente, à mercê da discricionariedade dos componentes.

$\mathrm{O}$ argumento apresentado na inicial, no que se refere ao mérito, tem duas partes: a primeira indica o que a ação não discute, ao passo que a segunda lista e embasa os argumentos que justificam a ação, ou seja, que demonstram como as cotas violariam os preceitos fundamentais anteriormente arrolados.

Assim, para uma melhor elucidação do que se propõe nessa análise de caso, convém fazer uma reconstrução das principais razões apresentadas. A ação não discute três questões:

a) a constitucionalidade das ações afirmativas como gênero e como política necessária para a inclusão de minorias e para o aprimoramento do Estado social-democrático de Direito;

b) o Brasil adota o modelo social de Estado;

c) a existência de racismo, de preconceito e de discriminação na sociedade brasileira.

De acordo com a parte autora, o que está em discussão, segundo a visão apresentada, é a implementação de um Estado racializado ou de um racismo institucionalizado. Assim, a política afirmativa adotada na UnB é racista, funda-se em uma visão idealizada da experiência estadunidense de cotas raciais e tem uma compreensão equivocada das relações raciais no Brasil. Enfim, o que se quer discutir é tão somente a constitucionalidade da implantação, no Brasil, do sistema de cotas baseadas na raça.

Explicando melhor a tese, sempre consoante os argumentos presentes na inicial: ${ }^{3}$ a raça isoladamente não pode ser critério razoável, legítimo e constitucional de diferenciação entre o exercício de direitos dos cidadãos, pois, no Brasil, diferentemente do que ocorreu nos EUA ou na África do Sul, a exclusão social decorre das precárias condições econômicas, e não exclusivamente por razões raciais. Por exemplo, os negros que integram a classe média alta não encontram muitas dificuldades para exercerem seus direitos e serem socialmente reconhecidos.

Desse modo, a instituição das cotas, na universidade ou em concursos públicos, não resolve o problema da exclusão social dos negros, apenas mascara a realidade, ou seja, não ataca o fato gerador do fenômeno, e pode agravar a situação, uma vez que instaura a consciência estatal da raça, promove a ofensa ao princípio da igualdade

\footnotetext{
3 Tais argumentos também aparecem em texto produzido pela representante do autor, Roberta Fragoso Menezes Kauffmann. Eles estão expressos no texto A desconstrução do mito da raça e a inconstitucionalidade das cotas raciais no Brasil (KAUFFMAN, 2010).
} 
ao estimular a discriminação inversa em relação aos brancos pobres, além de favorecer a classe média negra, que não necessariamente precisa de suporte estatal.

Outro argumento apresentado é o do critério da raça. Como definir alguém como negro? Pelo fenótipo ou pela ancestralidade genômica? De acordo com pesquisas lideradas por Pena (2005), a aparência de uma pessoa informa pouco sobre sua ancestralidade. Alguns negros possuem até $65 \%$ de ancestralidade europeia. Assim, "[...] no Brasil há brancos na aparência que são africanos na ancestralidade. E há negros, na aparência, que são europeus na ascendência." (PENA, 2005, p. 334). Além disso, a referida pesquisa demonstrou, em síntese, que apenas $20 \%$ dos brasileiros seriam, de fato, brancos puros. Logo, por existir uma forma de identificar objetivamente a ancestralidade genômica, não se devem utilizar outros critérios, que padeceriam de precisão.

Entretanto, o bônus de tal medida é muito inferior ao ônus que a aplicação desta provocaria. Além disso, teria que se indicar o grau de ancestralidade para se considerar alguém negro.

Os defensores dos programas afirmativos racialistas justificam tais medidas na teoria da Justiça compensatória. Esta afirma que falhas e injustiças cometidas contra indivíduos no passado devem ser reparadas. O princípio é simples: quando uma parte lesiona outra, tem o dever de reparar o dano, retornando a vítima à situação que se encontrava antes de sofrer a lesão. Desse modo, diz-se que os programas afirmativos para os afrodescendentes são os de resgatar a dívida que os brancos possuem com os negros por tê-los submetido à escravidão.

O problema de tal teoria reside em dois pontos: a dificuldade para responsabilizar, no presente, os brancos descendentes daqueles que, no passado, praticaram a escravidão; e, a dificuldade para identificar quem seriam os benificiários legítimos do programa compensatório. E, portanto, haveria o problema da responsabilização de quem não praticou o dano e a reparação seria efetivada para aqueles que não sofreram o dano. A tese é de que somente os que sofreram o dano diretamente podem pleitear a reparação. O maior risco decorrente desta é a da responsabilização ad infinitum. Em síntese, o núcleo central argumentativo exposto na inicial é esse.

Após os argumentos explicitados na petição inicial é necessário se destacar como o pedido de suspensão liminar foi apreciado pelo Ministro Gilmar Mendes.

\section{Argumentos usados para indeferir o pedido de suspensão liminar}

Em 31 de julho de 2009, ou seja, pouco mais de um mês após a interposição da Ação, o Ministro Gilmar Mendes, então na presidência do Supremo Tribunal Federal, indeferiu o pedido de suspensão liminar dos atos praticados pela UnB.

$\mathrm{O}$ argumento do Ministro Gilmar Mendes, em primeiro lugar, reconhece o caráter instigante e controverso da discussão sobre a legitimidade constitucional das ações afirmativas que implementam mecanismos de inclusão de minorias e determinados segmentos sociais, chegando a alegar se tratar a ADPF de uma das ques- 
tões constitucionais mais fascinantes do seu tempo, qual seja o "tempo dos direitos" cunhado por Bobbio. O motivo estaria associado ao fato de que referida temática remete às concepções individuais e coletivas que se tem sobre igualdade e liberdade, estas, valores centrais do Estado Democrático de Direito.

Em um segundo momento, para fundamentar sua posição, que será posteriormente evidenciada, acrescenta, partindo da tese defendida por Peter Häberle, que a fraternidade com a liberdade e a igualdade constituem os valores fundamentais propugnados pela Revolução Francesa de 1789.

De acordo com Mendes (BRASIL, 2009), a liberdade e a igualdade devem ser repensadas segundo o valor da fraternidade. Aquelas devem ser vistos a partir desta; em termos simples, a liberdade e a igualdade devem ser vistas segundo a ótica da fraternidade. Logo, essa é a chave para a solução de diversos problemas relacionados à igualdade e à liberdade.

A fraternidade possibilita que as questões controversas possam ser vistas na perspectiva do outro, estimulando, nas sociedades complexas e multiculturais, a tolerância. Nas palavras do Ministro:

[...] a tolerância nas sociedades multiculturais é o cerne das questões a que este século nos convidou a enfrentar em tema da liberdade e igualdade. Pensar a igualdade segundo o valor da fraternidade significa ter em mente as diferenças e particularidades humanas em todos os seus aspectos. A tolerância em tema de igualdade, neste sentido, impõe a igual consideração do outro em suas peculiaridades e idiossincrasias. Numa sociedade marcada pelo pluralismo, a igualdade só pode ser igualdade com igual respeito às diferenças. Enfim, no Estado Democrático, a conjugação dos valores da igualdade e fraternidade expressa uma normatividade constitucional no sentido de reconhecimento e proteção das minorias. (BRASIL, 2009).

Assim, pensar a igualdade, em sociedades plurais e multiculturais com Estado Democrático de Direito, demanda a consideração das diferenças e o reconhecimento e a proteção dos direitos das minorias.

Posteriormente, Mendes reconhece a necessidade de se garantir a igualdade material, contudo, sem desrespeitar outros valores constitucionais. Utilizando-se do Paradoxo da igualdade formulado por Alexy (2009), sustenta que este suscita problemas complexos para o exame da constitucionalidade das ações afirmativas em sociedades plurais.

Para lograr êxito na discussão sobre a constitucionalidade das ações afirmativas, é necessário considerar o contexto, as peculiaridades históricas e culturais de cada sociedade. Um modelo de ações afirmativas que funcionam em um Estado pode não ser oportuno ou conveniente em outro. Também é necessário aprofundar os estudos sobre o conceito de "raça" e as causas que originam preconceito racial no Brasil. Ademais, relevante à questão é considerar a necessidade de distinguir a discriminação promovida pelo Estado e a praticada pelos particulares. Por tais motivos, o Ministro indeferiu a liminar, razão pela qual aquele concurso vestibular teve seu 
devido prosseguimento sem qualquer alteração. Contudo, ainda falta deslindar os principais argumentos destacados no julgamento, aqueles proferidos em plenário.

\section{Argumentos e votos na Plenária do Supremo Tribunal Federal}

Antes de expor os argumentos e votos dos Ministros do STF, é importante registrar que no decorrer da tramitação da ação, diversas entidades e órgãos requisitaram ingresso na qualidade de amicus curiae. Os órgãos e entidades que ingressaram foram os seguintes: Educação e Cidadania de Afrodescendentes e Carentes (Educafro), Fundação Cultural Palmares, Movimento Negro Unificado, Movimento Pardo-Mestiço Brasileiro, Fundação Nacional do Índio (Funai), Instituto de Advocacia Racial e Ambiental, Defensoria Pública da União, Movimento Contra o Desvirtuamento do Espírito da Política de Ações Afirmativas nas Universidades Federais, Instituto de Direito Público e Defesa Comunitária Popular (Idep), Associação Nacional dos Advogados Afrodescendentes (Anaad), Conselho Federal da Ordem dos Advogados do Brasil e Associação Direitos Humanos em Rede.

Após a realização de audiências públicas e debates acadêmicos, a ADPF n. 186 foi levada ao plenário do Supremo Tribunal Federal em 26 de abril de 2012, para que, sob relatoria do Ministro Ricardo Lewandowski, os Ministros decidissem o mérito da questão levada à Suprema Corte naquela ação, qual seja pela constitucionalidade das cotas étnico-raciais como critério de ingresso no ensino superior público.

$\mathrm{Na}$ arguida UnB, o Advogado-Geral da União e o Procurador-Geral da República manifestaram-se pela improcedência da ação. $\mathrm{O}$ foco argumentativo recaiu sobre a tese de que o sistema de cotas implantado pela primeira permite a inclusão de parcela desfavorecida tanto pela renda quanto pela cor. Ademais, o segregacionismo velado existente no Brasil cria o mito da democracia racial e, por tal razão, deve ser combatido, equilibrando-se as disputas entre os variados grupos de brasileiros às mais diversas oportunidades sociais, pois os sistemas de cotas raciais iniciados pelas diversas universidades brasileiras têm ajudado a transformar o ambiente acadêmico em um lugar legitimamente plural, aumentando a participação de pretos e pardos nas universidades brasileiras, inclusive nos cursos de maior concorrência.

Em seguida à manifestação das Instituições mencionadas, os Ministros proferiram os seus votos. O primeiro a se manifestar foi o Ministro Ricardo Lewandowski, o Relator designado para essa ação. O Ministro apresentou seu voto em um desdobramento de 10 etapas:

a) primeira, destaca a dupla dimensão, formal e material, do princípio da igualdade agasalhado pela Constituição Federal de 1988;

b) segunda, defende a aplicação do princípio da igualdade segundo a Justiça distributiva nos moldes apresentados por John Rawls;

c) terceira, analisa o conceito de ação afirmativa e elenca os precedentes no STF sobre a temática em tela; 
d) quarta, discorre sobre os critérios jurídicos adotados no Brasil para o ingresso no ensino superior e a consciência étnico-racial como fator de exclusão;

e) quinta, comenta o papel integrador da Universidade;

f) sexta, tece observações sobre as ações afirmativas nos EUA;

g) sétima, apresenta a hetero e autoidentificação;

h) oitava, releva o tema da reserva de vagas ou estabelecimento de cotas;

i) nona, indica a transitoriedade das políticas das ações afirmativas;

j) décima, teoriza sobre a proporcionalidade entre meios e fins.

Após o destaque da estrutura formal da argumentação do Ministro Lewandowski, indica-se a síntese dos argumentos cruciais elencados para fundamentar a constitucionalidade das cotas étnico-raciais.

De acordo com ele, a efetivação do princípio constitucional de que todos são iguais perante a lei, sem distinção de qualquer natureza, somente é possível se for assegurada a igualdade material ou substancial para todos os cidadãos (1). Tal compreensão está explícita na evolução política, doutrinária e jurisprudencial brasileira. E a operacionalização daquela ocorre por intermédio das políticas afirmativas. Estas, por sua vez, possibilitam a igualdade de oportunidades.

A isonomia em igualdade de oportunidades ocorre quando há justiça distributiva (2). Esta permite a superação das desigualdades que ocorrem, na realidade, mediante a intervenção estatal e consistente para corrigi-las, realocando os bens e oportunidades existentes em vista do bem da coletividade. O modelo constitucional brasileiro aceita e compatibiliza-se com essa concepção.

Ao conceituar ação afirmativa (3), Lewandowski reforça o caráter transitório (9) delas, mas, diferentemente do que foi destacado na inicial, reforça, não deixando de lado outros critérios, a importância da variável etnia ou raça. No entanto, embora houvesse precedentes na Corte Brasileira sobre ações afirmativas, elas não versavam sobre cotas étnico-raciais.

No que se refere aos critérios de acesso ao ensino superior (4), a Constituição Federal brasileira indica os princípios que o regem (arts. 206 e 208). Não há um rol taxativo e nem certos critérios devem ser observados, embora haja a indicação de que o mérito de cada um deva ser considerado. De acordo com o Relator, esse critério precisa ser interpretado pelo princípio da igualdade material que permeia toda a Carta Magna. Assim, é “[...] essencial calibrar os critérios de seleção à universidade para que se possa dar concreção aos objetivos maiores colimados na Constituição. Nesse sentido, as aptidões dos candidatos devem ser aferidas de maneira a conjugar-se seu conhecimento técnico e sua criatividade intelectual ou artística com a capacidade potencial que ostentam para intervir nos problemas sociais."

Pode-se utilizar o parâmetro étnico-racial como critério de ingresso no ensino superior, uma vez que as raças, em termos biológicos, não existem? Tal argumento, da inexistência da raça como conceito biológico, não exclui a possibilidade do uso do critério, uma vez que se pode falar de um conceito histórico-cultural de 
raça, artificialmente construído, para justificar a discriminação ou, até mesmo, a dominação exercida por alguns indivíduos sobre certos grupos sociais, maliciosamente reputados inferiores. Ou seja, o racismo é um fato histórico-cultural. Não existem raças, em termos biológicos, mas o racismo, como construção histórico-cultural, é característica de diversas sociedades.

Esses e outros apenas mencionados são os argumentos que permitem ao Ministro Relator assim concluir que a instituição de cotas raciais cumpre o dever constitucional que atribui ao Estado a responsabilidade com a educação, assegurando acesso aos níveis mais elevados de ensino, pesquisa e criação científica, segundo a capacidade de cada um.

Assim, considerando principalmente que as políticas de ação afirmativa adotadas pela UnB tinham como objetivo estabelecer um ambiente acadêmico plural e diversificado, superando distorções sociais historicamente consolidadas e, nessa senda, revelavam proporcionalidade e razoabilidade no concernente aos meios empregados e aos fins perseguidos, além de serem transitórias, com previsão de revisão periódica de seus resultados, e, por fim, por empregarem métodos seletivos eficazes e compatíveis com o princípio da dignidade humana, julgou improcedente a ADPF.

Participaram desse julgamento, além do Relator, os Ministros: Luiz Fux, Rosa Weber, Cármen Lúcia, Joaquim Barbosa, Cezar Peluso, Gilmar Mendes, Marco Aurélio, Celso de Mello e Ayres Britto. Os Ministros, por unanimidade (10 votos), reconheceram a importância e a necessidade das ações afirmativas e declararam a constitucionalidade das cotas com base em critérios raciais. O principal argumento utilizado para sustentar a constitucionalidade das cotas foi o princípio da igualdade material, um dos elementos basilares dos Estados Democráticos de Direito.

Na sequência, um breve relato com o cerne dos votos dos outros Ministros. O Ministro Luiz Fux sustenta que a Constituição Federal impõe uma reparação de danos pretéritos do país para os negros, mormente a partir do art. $3^{\circ}$, I, que preconiza, entre os objetivos fundamentais da República, a construção de uma sociedade livre, justa e solidária. Outrossim, afirmou que,

\footnotetext{
[...] no Brasil, a pobreza "tem cor" e "os afrodescendentes (negros e pardos), que correspondem a mais de $50 \%$ da população do País, encontram-se em situação profundamente desvantajosa em relação aos brancos em todos os indicadores sociais relevantes - renda, níveis de analfabetismo, acesso a saneamento básico e serviços de saúde, taxa de mortalidade infantil, dentre outros".
}

A desigualdade, refere, “[...] decorre de um histórico de segregação e mazelas, em que a abolição da escravatura apenas serviu para trocar o negro de senhor: passou a ser escravo de um sistema feito para que nada mude, apesar das mudanças." Identifica-se, na posição do Ministro Fux, a necessidade de medidas que compensam as graves violações de direitos e a consequente exclusão social sofrida pelos negros. Assim, tem-que se tomar medidas, como aquela adotada pela UnB para igualar os desiguais. 
A Ministra Rosa Weber alegou caber ao Estado "[...] adentrar no mundo das relações sociais e corrigir a desigualdade concreta para que a igualdade formal volte a ter o seu papel benéfico”, pois, segundo ela, “[...] a desigualdade material, que justifica a presença do Estado nas relações sociais, só se legitima quando identificada concretamente, a impedir que determinado grupo ou parcela da sociedade usufrua das mesmas chances de acesso às oportunidades sociais de que beneficiários outros grupos." Assim, menciona que as universidades devem ampliar o número de negros em seus quadros com o sistema de cotas raciais, propiciando, assim, maior e melhor representatividade social no ambiente acadêmico, tornando-se mais plural e democrático.

A Ministra Cármen Lúcia Antunes Rocha, por seu turno, ressaltou que o sistema de cotas é perfeitamente compatível com a Constituição de 1988, pois observa a proporcionalidade, assegura a igualdade material e a função social da universidade. $\mathrm{Na}$ avaliação da Ministra, a situação dos negros no Brasil não pode ser ignorada. Afirma ela: "Tantas vezes decantada, a igualdade é o princípio mais citado na Constituição Federal. Quem sofre preconceito percebe que os princípios constitucionais viram retórica." Além disso, destacou que a Constituição Federal de 1988 inovou ao entender o princípio da igualdade como um processo dinâmico da igualação. Ela frisou, ainda, que as ações afirmativas, como as cotas raciais, fazem parte da responsabilidade social e estatal para que se cumpra o princípio da igualdade.

O Ministro Joaquim Barbosa entende que as ações afirmativas, como aquela adotada pela UnB, são políticas públicas voltadas à concretização do princípio constitucional da igualdade material e à neutralização dos efeitos perversos da discriminação racial, de gênero, de idade, de origem nacional e de compleição física. E portanto, ressaltou, com elas: "A igualdade deixa de ser simplesmente um princípio jurídico a ser respeitado por todos, e passa a ser um objetivo constitucional a ser alcançado pelo Estado e pela sociedade."

Prosseguindo com o julgamento, o Ministro Cezar Peluso proferiu seu voto. Destacou que é fato sócio-histórico incontroverso o déficit educacional e cultural da etnia negra, observado desde os primórdios do processo histórico da vida brasileira, em virtude das graves e conhecidas barreiras institucionais de acesso dos negros às fontes da educação e da cultura. Por isso que existe um

[...] dever, que não é apenas ético, mas também jurídico, assim do Estado, como da sociedade toda, perante tamanha desigualdade, à luz dos objetivos fundamentais da República, como está no artigo $3^{\circ}$ da Constituição Federal, que se propõe, em primeiro lugar, a construir uma sociedade solidária; em segundo lugar, a erradicar a marginalização e reduzir as desigualdades sociais; e, em terceiro lugar, promover o bem de todos sem preconceito de raças. São objetivos textuais da Constituição.

Em outros termos, as cotas étnico-raciais são constitucionais, pois possibilitam a erradicação ou pelo menos propiciam a diminuição das desigualdades.

Gilmar Mendes, por sua vez, considerou que as ações afirmativas são formas de aplicação do princípio da igualdade. Para ele, o número reduzido de negros 
nas universidades é resultado de um processo histórico que decorre do modelo escravocrata de desenvolvimento, além da baixa qualidade da escola pública, o que se soma ao fato de que apenas quem passou pelas escolas privadas terá condições de enfrentar o sistema de vestibular que, para ele, em alguns casos é um concurso de dificuldade quase que lotérica.

O Ministro Marco Aurélio afirmou que as ações afirmativas devem ser utilizadas na correção de desigualdades, mas que elas devem ser extintas tão logo essas diferenças sejam eliminadas. Ademais, afirmou que apenas existe supremacia da Constituição quando, à luz dela, vingar a igualdade. E, nesse caso, a ação afirmativa evidencia o conteúdo democrático do princípio da igualdade jurídica.

Celso de Mello, por seu turno, defendeu que o sistema adotado pela Universidade de Brasília obedece à Constituição Federal e aos tratados internacionais que tratam da defesa dos direitos humanos. Para ele, "[...] o desafio não é apenas a mera proclamação formal de reconhecer o compromisso em matéria dos direitos básicos da pessoa humana, mas a efetivação concreta no plano das realizações materiais dos encargos assumidos."

Por fim, o Ministro Ayres Britto, Presidente do STF à época, confirmou que a Constituição legitimou todas as políticas públicas para promover os setores sociais histórica e culturalmente desfavorecidos. Segundo o Ministro, “[...] o princípio da unidade da Constituição chancela as políticas públicas de promoção racial, são ações afirmativas da intrínseca, da inata dignidade de todo o ser humano, independentemente da cor de sua pele", vale dizer, “[...] são políticas afirmativas desse direito de transitar com o mesmo desembaraço pelos espaços - volto a dizer - institucionais ou até espaciais de que a sociedade se compõe", pois “[...] assim é que se constrói uma nação; assim é que se constrói, com dignidade, uma nação.”

Portanto, o Plenário do Supremo Tribunal Federal decidiu, por unanimidade, que a possibilidade de o Estado lançar mão de políticas de cunho universalista, que abrangem um número indeterminado de indivíduos, a partir de ações de natureza estrutural, bem como de ações afirmativas, que atingem grupos sociais determinados, de modo pontual, atribuindo-lhes vantagens, por tempo determinado, a fim de permitir-lhes a superação de desigualdades decorrentes de situações históricas particulares não contraria, em vez disso, prestigia o princípio da igualdade material.

Nesses termos, o princípio da igualdade material destaca-se como o epicentro da fundamentação plural usada para assegurar por unanimidade as constitucionalidades das cotas raciais. Pelo papel central na ADPF analisada, o referido princípio faz jus a um melhor esclarecimento. 


\section{0 princípio da igualdade ${ }^{4}$}

Entre os conceitos que se caracterizam pelo caráter abrangente, indeterminado e polissêmico está o de igualdade. A abrangência, a indeterminação e a polissemia do conceito de igualdade estão associadas ao sentido e ao significado que a ele se atribuem. Atribuição essa que depende de fatores intra e/ou extralinguísticos. Por exemplo, contextos sócio-históricos são importantes, em algumas situações, na atribuição do sentido e do significado do que é igual e o seu alcance.

Quando se fala no ideal/princípio da igualdade, imediatamente, questões se descortinam:

a) o que é o igual? É o recíproco ou é o proporcional?

b) Que tipo de igualdade está sendo mencionada ou pressuposta: a econômica, a política, a social, a jurídica? Igualdade formal ou igualdade material? Igualdade "simples" ou "complexa"?

Antes de se apresentar e se explicitar adequadamente a "noção" de igualdade material, faz-se uma breve síntese histórica sobre esta. Contudo, antes de iniciar o resgate histórico, é importante frisar que a igualdade aqui é entendida como um ideal político, no sentido kantiano de ideia reguladora. Além disso, é uma virtude, soberana, da comunidade política (DWORKIN, 2011). Em resumo, a igualdade é um ideal e uma virtude política.

O ideal ou a virtude da igualdade, em sua dimensão política, é um valor estimado pelos indivíduos desde os primórdios da civilização ocidental. O exemplo histórico notório é a democracia grega. Claro que devem ser feitas todas as ressalvas possíveis em relação a esse modelo. O importante para a análise é o fato de que na Grécia antiga, mormente em Atenas, tem-se a primeira experiência política democrática, na qual a igualdade entre os cidadãos era um dos seus traços característicos. Assim, a igualdade não é uma novidade moderna. Embora, cabe o registro de que a natureza, a extensão e o alcance dela sejam completamente diferentes na antiguidade.

A mais importante e significativa tematização da igualdade na Grécia antiga foi levada a cabo por Aristóteles. Para ele, a igualdade buscada na pólis dependia principalmente da justiça, que é uma virtude ${ }^{5}$ e se divide em duas classes: a corretiva e a distributiva (ARISTÓTELES, 2009).

Segundo Aristóteles, a justiça corretiva trata da relação entre particulares, entre os iguais e, nesse âmbito, os iguais devem ser tratados de forma igual. Por outro lado, na justiça distributiva, que envolve uma relação do tipo Estado-indivíduo - na qual o primeiro distribui bens, honrarias e outros -, os desiguais devem ser tratados de

\footnotetext{
4 Argumentos apresentados e desenvolvidos em Tramontina e Silva (2014).

5 Diz Aristótele (2009, p. 103): "A justiça é aquela disposição de caráter que torna as pessoas propensas a fazer o que é justo, que as faz agir justamente e a desejar o que é justo."
} 
forma desigual. Deve-se atribuir a cada um segundo o seu valor, o seu mérito, ou seja, utiliza-se de critério da proporcionalidade. ${ }^{6}$ Assim, há uma sugestão na compreensão aristotélica, não desenvolvida, de que a igualdade possui uma dupla dimensão.

Ao pensamento aristotélico, na Roma antiga, opuseram-se Cícero e Sêneca. Ambos defenderam a ideia da igualdade universal entre os homens. De acordo com eles, todos os seres humanos são universalmente iguais.

De forma sintética, pode-se sustentar que as principais teses do pensamento antigo (greco-romano) sobre a igualdade são as seguintes:

a) todos os homens são naturalmente iguais (tese estoica, não aristotélica);

b) ela é a essência da justiça;

c) ela pressupõe a comparação e não tem sentido entre coisas não comparáveis;

d) obriga a tratar o igual igualmente, e desigualmente o desigual;

e) é a base da democracia (ALBUQUERQUE, 1993).

É incontroverso de ser na modernidade que o ideal da igualdade passa a ocupar lugar central, com a liberdade, na teoria política. É conhecida a tese contratualista, embora haja diferenças importantes entre os principais representantes dessa corrente - Hobbes (2003), Locke (1998) e Rousseau (1999) -, de que os homens são naturalmente livres e iguais. A formulação da tese, nos termos expostos por Rousseau (1999), constitui a base da teoria democrática republicana.

A teorização filosófica política fornece a base necessária para que o princípio da igualdade emerja como categoria jurídica nos documentos constitucionais promulgados após as revoluções do final do século XVIII. Nesses documentos, especialmente nos EUA e na França, edificou-se o conceito de igualdade perante a lei, geral e abstrata, que deve ser igual para todos sem qualquer distinção ou privilégio. Esse conceito de igualdade formal é a ideia-chave do constitucionalismo do século XIX e meados do século XX (GOMES, 2003a).

Contudo, o reconhecimento da igualdade formal não consegue atender ao “paradoxo da liberdade". Assim, é necessário que o princípio da igualdade seja explicitado em sua dupla dimensão: formal e material.

\section{Igualdade formal versus igualdade material}

Como destacado, a tese de que a igualdade tem uma dupla dimensão ${ }^{7}$ pode ser localizada na abordagem aristotélica. A ideia básica é de que os iguais devem ser

\footnotetext{
${ }_{6} \quad$ É importante observar que a teoria aristotélica precisa ser analisada e utilizada com certa parcimônia, dado seu compromisso com alguns pressupostos filosóficos e políticos atualmente indefensáveis, por exemplo: a tese de que a desigualdade e a escravidão são naturais e, portanto, justas.

7 Isso não sugere que Aristóteles fez a distinção entre igualdade formal e igualdade material. Além do mais, é importante frisar, a dupla dimensão da noção de igualdade na teoria aristotélica, em termos morais e políticos, justifica
} 
tratados de forma igual, e os desiguais de forma desigual. A noção de igualdade varia de acordo com o tipo de relação que se estabelece.

As formulações filosóficas (Locke (1998), Montesquieu (1980), Rousseau (1999) modernas acerca da igualdade, após certo lapso temporal, restam recepcionadas e institucionalizadas juridicamente. Isso pode ser identificado nas Constituições elaboradas nesse período. Entretanto, a positivação do "direito natural" à igualdade se restringiu há uma das dimensões da igualdade, a formal. Assim, influenciadas pelo liberalismo vigente à época, as normas jurídicas basilares asseguraram a igualdade de todos perante a lei. Em outros termos, diante da lei, todos são iguais.

A igualdade formal é característica de um Estado Liberal, pois reflete aquela prevista em lei, isto é, diante dos ordenamentos jurídicos todos são iguais perante a lei, sem que possa haver qualquer tipo de discriminação, ou, então, haver tratamentos desiguais entre iguais. ${ }^{8}$ Trata-se de igualdade meramente processual (GOMES, 2003a).

Como destacado, esse tipo de igualdade é característica do Estado Liberal, pois, segundo a concepção que fundamenta tal configuração, assim como expressa, por exemplo, em Smith (1989) (Liberalismo econômico) e Locke (1998) (Liberalismo político), o aparato estatal somente deve garantir aos seus cidadãos direitos individuais, como direitos políticos, públicos e de liberdade. As revoluções liberais pretendiam assegurar a igualdade jurídica e não a igualdade das condições de fato (FERREIRA FILHO, 2010).

Entretanto, em virtude do processo de pauperização da população mundial, decorrente da Primeira Grande Guerra Mundial, bem como da quebra da Bolsa de Valores de Nova York em 1929, especialmente na Europa, a natureza e o papel do Estado são repensados. O Estado, a partir da década de 1930, passa a preocupar-se em intervir significativamente nos diversos setores da sociedade, e assume a função de propulsor, garantidor positivo e efetivador de direitos sociais, econômicos e culturais.

No interior desse contexto histórico, em meados do século XX, há o cenário jurídico sobre significativas modificações. Com o Estado Social de Direito, além dos direitos civis, individuais e políticos, tem-se os direitos sociais, econômicos e culturais.

As Constituições criadas nesse período, especialmente, a mexicana e a alemã, basearam-se nesse novo modelo de Estado, isto é, nos ideais sociais que iniciaram a uma nova ordem mundial. Desse modo, segundo Melo (1998, p. 84), “[...] o princípio da igualdade passa a ter um novo contorno, incorporando a igualdade material e seguindo no rumo da chamada discriminação positiva." Logo, a igualdade material, a outra dimensão da igualdade, ganha corpo e efetividade.

a desigualdade, que para Aristóteles era natural.

8 A teoria constitucional clássica, herdeira do pensamento de Locke, Rousseau e Montesquieu, é a responsável pelo florescimento de uma concepção meramente formal de igualdade - a chamada de igualdade perante a lei. Trata-se de uma realidade de uma igualdade meramente processual (GOMES, 2003a, p. 40). 
Em que a igualdade material difere da igualdade formal? É a natureza e o aspecto da relação que indicam a dimensão da igualdade que se trata ou se deve considerar. De acordo com Hesse (1991, p. 131): "A igualdade material não consiste em um tratamento igual sem distinção e todos em todas as relações, senão, só aquilo que é igual deve ser tratado igualmente. O princípio da igualdade proíbe uma regulação desigual para fatos iguais; casos iguais devem encontrar regra igual."

Assim, o tratamento diferenciado dos desiguais se equipara formalmente com o tratamento igual dos iguais e não viola a ideia central do tratamento isonômico, pelo menos em termos distributivos.

Em termos jurídicos, a aplicação da igualdade material se justifica diante das desigualdades. Existem desigualdades que, quando percebidas, indicam a necessidade de que é urgente e oportuno que a igualdade real ou material se realize, ou seja, é relevante que ocorra a igualização das condições desiguais. Disso se extrai que a lei geral, abstrata e impessoal, ao incidir em todos, igualmente, considerando apenas a igualdade dos indivíduos, e não a igualdade dos grupos, acaba por produzir mais desigualdades e propiciar a injustiça. Igualdade substancial, portanto, é a busca da igualdade de fato, da efetivação, da concretização dos postulados da igualdade perante a lei (igualdade formal).

Verifica-se, assim, que a igualdade material prevê, indiretamente, a criação de institutos capazes de acabar com as desigualdades que a própria igualdade formal deu causa ou não é suficiente para resolver.

A igualdade material deve ser entendida como uma maneira de propiciar tratamento equânime e uniforme aos cidadãos, bem como sua equiparação no referente às possibilidades de acesso a oportunidades de qualquer natureza.

Dessa forma, denota-se que as legislações produzidas consoantes à concepção liberal, primeiramente, garantiram a todas as pessoas a igualdade perante a lei, sem distinção individual ou em grupos, isto é, a igualdade formal. Mais tarde, percebeu-se, pelo contexto fático, que somente esse tipo de igualdade não era suficiente para conseguir garantir tratamento igualitário para todas as pessoas. Surgiu, assim, a igualdade dos casos concretos, a chamada de igualdade material que visa à efetivação da igualdade entre as pessoas, vez que a igualdade formal não é suficiente para combater algumas desigualdades existentes (GOMES, 2003b).

Assim, para se efetivar o princípio da igualdade, há a necessidade/dever de se criarem institutos com o fito de equilibrar as relações sociais, políticas e econômicas existentes. Por essa razão, a decisão do STF, razoável e adequada, que declarara a constitucionalidade da reserva de vagas para negros em universidades públicas, é um passo significativo nessa direção.

\section{Referências}

ALBUQUERQUE, Martim de. Da igualdade: Introdução à Jurisprudência. Coimbra: Livraria Almedina, 1993. 
ALEXY, Robert. Teoria dos direitos fundamentais. São Paulo: Malheiros, 2009.

ARISTÓTELES. Ética a Nicômaco. São Paulo: Atlas, 2009.

BRASIL. Supremo Tribunal Federal. Ação por Descumprimento de Preceito Fundamental n. 186. Relator: Ministro Ricardo Lewandowski. Brasília, DF, 26 abr. 2012. Disponível em: <http://www.stf.jus.br//arquivo/ informativo/documento/informativo663>. Acesso em: 20 abr. 2015.

BRASIL. Supremo Tribunal Federal. Medida Cautelar em Ação por Descumprimento de Preceito Fundamental n. 186-2. Relator: Ministro Gilmar Mendes. Brasília, DF, 31 jul. 2009. Disponível em: < http://www.acoes. ufscar.br/admin/legislacao/arquivos/ arquivo13.pdf $>$. Acesso em: 20 abr. 2015.

DWORKIN, Ronald. A Virtude Soberana: a teoria e a prática da igualdade. São Paulo: Martins Fontes, 2011.

FERREIRA FILHO, Manoel Gonçalves. Princípios Fundamentais do Direito Constitucional. 10. ed. São Paulo: Saraiva, 2010.

GOMES, Joaquim Barbosa. As ações afirmativas e os processos de promoção da igualdade. SEMINÁRIO INTERNACIONAL AS MINORIAS E O DIREITO. 1., 2003. Brasília, DF. Anais... Brasília, DF, 2003a. v. 24.

GOMES, Joaquim Barbosa. O debate constitucional sobre as ações afirmativas. IN: SANTOS, Renato Emerson dos; LOBATO, Fátima. Ações afirmativas: Políticas públicas contra as desigualdades raciais. Rio de Janeiro: DP\&A, 2003b.

HESSE, Konrad. A força normativa da constituição. Porto Alegre: Sérgio Antônio Fabris, 1991.

HOBBES, Thomas. Leviatã. São Paulo: Martins Fontes, 2003.

KAUFFMAN, Roberta Fragoso Menezes. A desconstrução do mito da ração e a inconstitucionalidade de cotas raciais no Brasil. DPU. n. 36, nov./dez. 2010.

LOCKE, John. Dois tratados sobre o Governo. São Paulo: Martins Fontes, 1998.

MONTESQUIEU. Do Espírito das Leis. 2. ed. São Paulo: Abril Cultural, 1980.

PENA, Sérgio. Razões para banir o conceito de raça da medicina brasileira. História, Ciências, Saúde, Manguinhos, v. 12, n. 1, p. 321-46, maio/ago. 2005.

ROUSSEAU. Do Contrato Social. São Paulo: Nova Cultural, 1999. 
SMITH, Adam. Inquérito sobre a natureza e as causas da riqueza das nações. 2. ed. Londres: Fundação Calouste Gulbenkian, 1989. v. 2.

TRAMONTINA, Robison; SILVA, Rogério Néri da. O debate em torno das cotas raciais como critério para o ingresso no Ensino Superior: Considerações acerca da Ação por Descumprimento de Preceito Fundamental (ADPF) 186. Direitos Fundamentais \& Justiça, v. 28, p. 190-208, 2014.

Data da submissão: 16 de agosto de 2015 . Aceito em: 16 de agosto de 2015 
